\title{
Anti-interleukin-33 Reduces Ovalbumin-Induced Nephrotoxicity and Expression of Kidney Injury Molecule-1
}

\author{
Geun Ho Park ${ }^{1, *}$, Helen Ki Shinn ${ }^{2, *}$, Ju-Hee Kang ${ }^{1}$, Won Ju Na², Young Hyo Kim³, Chang-Shin Park ${ }^{1}$ \\ ${ }^{1}$ Department of Pharmacology, Hypoxia-Related Disease Research Center, Inha Research Institute for Medical Sciences, Inha University College of Medicine, \\ Incheon, Korea \\ ${ }^{2}$ Department of Anesthesiology and Pain Medicine, Inha University College of Medicine, Incheon, Korea \\ ${ }^{3}$ Department of Otorhinolaryngology, Head and Neck Surgery, Inha University College of Medicine, Incheon, Korea
}

Purpose: To evaluate the effect of anti-interleukin-33 (anti-IL-33) on a mouse model of ovalbumin (OVA)-induced acute kidney injury (AKI).

Methods: Twenty-four female BALB/c mice were assigned to 4 groups: group A (control, $n=6$ ) was administered sterile saline intraperitoneally (i.p.) and intranasally (i.n.); group B (allergic, $n=6$ ) was administered i.p./i.n. OVA challenge; group C (null treatment, $\mathrm{n}=6$ ) was administered control IgG i.p. before OVA challenge; and group D (anti-IL-33, $\mathrm{n}=6$ ) was pretreated with $3.6 \mu \mathrm{g}$ of anti-IL-33 i.p. before every OVA challenge. The following were evaluated after sacrifice: serum blood urea nitrogen and creatinine levels, Kidney injury molecule-1 gene (Kim-1) and protein (KIM-1) expression in renal parenchyma, and expression of cyclooxygenase-2 (COX-2), inducible nitric oxide synthase (iNOS), phosphorylated endothelial NOS (p-eNOS), and phosphorylated AMP kinase (p-AMPK) proteins in renal parenchyma.

Results: After OVA injection and intranasal challenge, mice in groups B and C showed significant increases in the expression of Kim-1 at both the mRNA and protein levels. After anti-IL-33 treatment, mice in group D showed significant Kim-1 downregulation at the mRNA and protein levels. Group D also showed significantly lower COX-2 protein expression, marginally lesser iNOS expression than groups B and C, and p-eNOS and p-AMPK expression at baseline levels.

Conclusions: Kim-1 could be a useful marker for detecting early-stage renal injury in mouse models of OVA-induced AKI. Further, anti-IL-33 might have beneficial effects on these mouse models.

Keywords: Acute Kidney Injury; Interleukin-33; Ovalbumin; Kidney Injury Molecule-1

- Grant Support: This study was supported by Inha University Research grants (2015).

- Research Ethics: All mice used in this study were handled in accordance with a protocol approved by Inha University Institutional Animal Care and Use Committee (approval number. INHA 130404-201).

- Conflict of Interest: No potential conflict of interest relevant to this article was reported.

Corresponding author: Chang-Shin Park (D) http://orcid.org/0000-0001-6519-2857 Department of Pharmacology, Hypoxia-Related Disease Research Center, Inha Research Institute for Medical Sciences, Inha University College of Medicine, 100 Inha-ro, Nam-gu, Incheon 22112, Korea

E-mail: parkshin@inha.ac.kr / Tel: +82-32-860-9871 / Fax: +82-32-890-3580

Co-corresponding author: Young Hyo Kim (iD http://orcid.org/0000-0002-3623-1770 Department of Otorhinolaryngology, Head and Neck Surgery, Inha University College of Medicine, 27 Inhang-ro, Jung-gu, Incheon 22332, Korea

E-mail: inhaorl@inha.ac.kr / Tel: +82-32-890-2437 / Fax: +82-32-890-3580

* Geun Ho Park and Helen Ki Shinn contributed equally to this study as co-first authors

Submitted: March 17, 2016 / Accepted after revision: April 27, 2016
This is an Open Access article distributed under the terms of the Crecc
commons.org/licenses/by-nc/4.0/) which permits unrestricted non-commercial use, distribution, and reproduction in any medium, provided the original work is properly cited. 


\section{INTRODUCTION}

Interleukin (IL)-33 is a member of the proinflammatory cytokine IL-1 superfamily [1]. IL-33 receptor (ST2 or orphan receptor) is expressed on epithelial and endothelial cells [2]. Binding of IL-33 to ST2 induces inflammatory response via activation of downstream signaling cascades - the nuclear factor-kappa B (NF- $\mathrm{KB}$ ) and mitogen-activated protein (MAP) kinase pathways [3]. The enzymatic cleavage sites for caspases 3 and 7 , and calpain in IL-33 are located within its cytokine domain, and during apoptosis, cleavage products of IL-33 are rendered biologically inactive [4]. On the other hand, the intact IL-33 is released in necrotic cell death, which binds to ST2, and activates NF- $\mathrm{kB}$ and MAP kinase pathway; this suggests that IL-33 could function as an 'alarmin' [5].

The lumens of renal tubules are composed of epithelial cells, and hence, it is reasonable to expect that IL-33 and renal tissue injury are associated. Several researchers have suggested that serum IL-33 levels and the severities of chronic renal disorders are interrelated [6,7]. However, a detailed review of literature showed that the effect of blocking IL-33 in the clinical course of acute kidney injury (AKI) has not been previously examined.

Therefore, in the present study, we aim to evaluate the effect of anti-IL-33 in an ovalbumin (OVA)-induced model of AKI. Our first step was to set up an OVA-induced AKI model in mice. Several murine models of AKI have been developed previously: AKI can be induced by the 'ischemia-reperfusion injury' model that involves clamping renal pedicles for about 35 minutes [8], or by the 'cisplatin-induced AKI' model in which cisplatin is injected intraperitoneally (i.p.) [7]. However, these models cause severe kidney injury and are representative of specific conditions such as ischemia-reperfusion or chemical injury. A recent study has also proposed that allergic and renal disorders are related [9]. In this study, we induced a mild form of AKI by OVA i.p. and intranasally (i.n.) instillation.

Blood urea nitrogen (BUN) and creatinine are traditional markers for renal injury, but have low sensitivity to AKI [10]. Kim-1 was found to be a potentially useful marker for AKI [11]. cyclooxygenase-2 (COX-2) is expressed at low baseline levels in the renal parenchyma under normal conditions. However, in response to inflammation and AKI, there is increased induction of COX-2 [12,13]. Furthermore, COX-2-deficient mice have an increased tendency to develop AKI [14]. Likewise, cisplatin-induced AKI can activate AMP-activated protein kinase (AMPK), and inhibition of AMPK can lead to repressed au- tophagy and eventually, further DNA damage [15]. After successful induction of AKI by OVA challenge, we evaluated these markers and the expression levels of the mRNAs and proteins of Kim-1, and of COX-2, nitric oxide synthase (iNOS), phosphorylated endothelial NOS (p-eNOS), and phosphorylated AMPK (p-AMPK) in the renal parenchyma.

\section{MATERIALS AND METHODS}

\section{Animals}

Twenty-four 8- to 10-week-old female BALB/c mice, free of murine-specific pathogens, were purchased from Orient Bio (Seongnam, Korea). The mice were raised in a specific pathogen-free environment with unrestricted access to OVA-free food and water under a 12-hour light/dark cycle. All mice used in this study were handled in accordance with a protocol approved by Inha University Institutional Animal Care and Use Committee (approval number. INHA 130404-201).

\section{Sensitization and Antigen Challenge}

To induce allergic rhinitis, the mice were sensitized and subjected to antigen challenge as previously described, with slight modification to the procedure $[16,17]$. Briefly, mice were sensitized with an intraperitoneal injection of OVA $(40 \mu \mathrm{g} / \mathrm{kg}$; Sigma-Aldrich, St. Louis, MO, USA), diluted in sterile saline containing alum adjuvant $(40 \mathrm{mg} / \mathrm{kg}$ ) on experimental days (EDs) $1,5,14$, and 21 . Mice were subjected to daily intranasal challenge with OVA ( $20 \mu \mathrm{L}$ of $25 \mathrm{mg} / \mathrm{mL}$ OVA per mouse) from ED 22 to ED 35.

For blocking experiments, we used antimouse anti-IL-33 antibody (Mouse IL-33 specific IgG), produced in goats, and immunized with purified Escherichia coli-derived recombinant mature mouse IL-33 (R\&D Systems, Minneapolis, MN, USA). Anti-IL-33 antibody ( $3.6 \mu \mathrm{g} /$ mouse) was injected i.p., $30 \mathrm{~min}$ utes before every OVA sensitization and intranasal challenge (a total of 18 times). For null treatment controls, 6 OVA-challenged mice received the same amount of control IgG i.p. (R\&D Systems). In group A ( $n=6$, control group), mice were sensitized and challenged i.p. and i.n. with sterile saline. Mice in group B ( $n=6$, allergic group) were subjected to i.p. and i.n. OVA challenges. In group $C(n=6$, null treatment group), control IgG was injected i.p. before OVA challenge. Finally, in group $\mathrm{D}(\mathrm{n}=6$, anti-IL-33 group), animals were pretreated i.p. with anti-IL-33 antibody before every OVA challenge. 


\section{Serum Collection, and BUN and Creatinine Measurement}

Twenty-four hours after the last OVA challenge on ED 36, all mice were sacrificed by cervical dislocation and serum samples were obtained by aortic puncture. Serum BUN and creatinine levels were measured using commercially available kits (Teco Diagnostics, Anaheim, CA, USA) and an auto-analyzer (model 99 M chemistry analyzer, Medispec, Palm City, FL, USA).

\section{RNA Extraction and cDNA Synthesis}

Total RNA was extracted using TRI Reagent (Sigma-Aldrich Korea, Yongin, Korea), according to the manufacturer's instructions, and then resuspended in diethyl pyrocarbonate water. Final RNA amounts were determined spectrophotometrically at $260 / 280 \mathrm{~nm}$. RNA quality was assessed by the presence of the $18 \mathrm{~S}$ and $28 \mathrm{~S}$ band smears, analyzed using a Bioanalyzer 2100 (Agilent Technologies, Santa Clara, CA, USA). RNA samples were stored at $-70^{\circ} \mathrm{C}$ until required. cDNAs were synthesized from $2 \mu \mathrm{g}$ of total RNA, with SuperScript II RNase H reverse transcriptase (Invitrogen, Carlsbad, CA, USA), according to the manufacturer's instructions.

\section{Real-Time Polymerase Chain Reaction}

Real-time quantitative polymerase chain reaction (PCR) was performed in the ABI Prism 7900 Sequence Detection System (PE Applied Biosystems, Foster City, CA, USA), in white 384well plates (ABgene, Hamburg, Germany), which provided 3 -fold intensification of fluorescent signals. The system operates using a thermal cycler and a laser that is directed to each of the 384 sample wells. Emission from each sample was collected by a charge-coupled device camera, and data were analyzed using Sequence Detection System software (SDS ver. 2.2, PE Applied Biosystems).

Reaction mixtures contained $375 \mathrm{nmol} / \mathrm{L}$ of each primer and 2X SYBR Green PCR Master Mix (PE Applied Biosystems), which included HotStarTaq DNA-Polymerase in an optimized buffer, dNTP mix (containing dUTP as additive), SYBR Green I fluorescent dye, and ROX dye (for passive reference). Each of the 384-well real-time quantitative PCR plates contained $5 \mu \mathrm{g}$ of cDNA. Primers were amplified using the same conditions. The primers sequences are as follows: for GAPDH, forward 5'-TGGC ACAGTCAAGGCTGAGA-3' and reverse 5'-CTTTGAGTGGC AGTGATGG-3'; for Kim-1, forward 5'-ATGCCCATCTTCT GCTTGTCA- $3^{\prime}$ and reverse 5'-CCTTGTAGTTGTGGGTC TTGT- $3^{\prime}$. Thermal cycling conditions were $50^{\circ} \mathrm{C}$ for 2 minutes and $95^{\circ} \mathrm{C}$ for 10 minutes followed by 40 cycles of $95^{\circ} \mathrm{C}$ for 30 seconds, $60^{\circ} \mathrm{C}$ for 30 seconds, and $72^{\circ} \mathrm{C}$ for 30 seconds.

\section{Western Blot Analysis}

Kidney tissues (left whole kidneys) were homogenized in lysis buffer (320mM sucrose, 200mM 4-(2-hydroxyethyl)-1-piperazineethanesulfonic acid, $1 \mathrm{mM}$ ethylenediaminetetraacetic acid, $\mathrm{pH}$ 7.2), protease inhibitor cocktail (Sigma-Aldrich Korea), and phosphatase inhibitor cocktail (Sigma-Aldrich Korea), using a Teflon homogenizer. Cellular debris was removed from homogenates by centrifuging at $3,000 \mathrm{rpm}$ at $4^{\circ} \mathrm{C}$ for 10 minutes. Total protein contents were determined using a bicinchoninic acid protein assay kit (Thermo Fisher Scientific, Rockford, IL, USA). Proteins were separated by sodium dodecyl sulfate (SDS)-polyacrylamide gel electrophoresis $(10 \mu \mathrm{g})$ and transferred onto polyvinylidene difluoride membranes in a transfer buffer containing $250 \mathrm{mM}$ Tris- $\mathrm{HCl}, 4 \%$ SDS, $40 \%$ glycerol, $0.02 \%$ bromophenol blue, and 20\% 1,4-dithiothreitol. Membranes were then blocked with $5 \%$ bovine serum albumin in Tris-buffered saline containing $0.1 \%$ Tween- 20 for 1 hour, incubated with specific primary antibodies for 24 hours, and then incubated with goat antirabbit (1:5,000, Thermo Fisher Scientific), rabbit antigoat (1:5,000, Invitrogen), or goat antimouse (1:10,000, Thermo Fisher Scientific) IgG HRP secondary antibodies. Immunoreactive bands were visualized using an enhanced chemiluminescence kit (Thermo Fisher Scientific), and analyzed using Bio-1D software (SIM International Group, Newark, DE, USA).

\section{Statistical Analyses}

The Kruskal-Wallis and Mann-Whitney U-tests were performed to determine statistically significant differences between the groups. We used IBM SPSS Statistics ver. 19.0 (IBM Co., Armonk, NY, USA) for the statistical analyses; P-values $<0.05$ were considered significant.

\section{RESULTS}

\section{Anti-Allergic Effect of Anti-IL-33 on a Mouse Model of Allergic Rhinitis}

Several parameters were analyzed to study the effect of antiIL-33: nose-scratching behavior, serum total and OVA-specific IgE, number of inflammatory cells (eosinophils, neutrophils, and lymphocytes), and Th2 cytokine (IL-4, IL-5, and IL-13) titers in bronchoalveolar lavage fluid. Mice in group $\mathrm{B}$ (the allergic group, intraperitoneal and intranasal OVA challenge) showed a 
significant increase in all the parameters versus group A (control group, sensitized and challenged with saline only). Mice in group C (null treatment group) showed no improvement in these parameters after the i.p. administration of control IgG. After anti-IL-33 treatment, mice in group D (anti-IL-33 group) exhibited significant improvements in all parameters. Our findings in this study are similar to results in our previous studies $[16,18]$.

\section{Changes in Serum BUN and Creatinine Levels}

As illustrated in Fig. 1, after induction of allergic rhinitis with OVA, groups B and C showed no significant increases in serum BUN and creatinine levels as compared to group A $(\mathrm{P}>0.05)$.
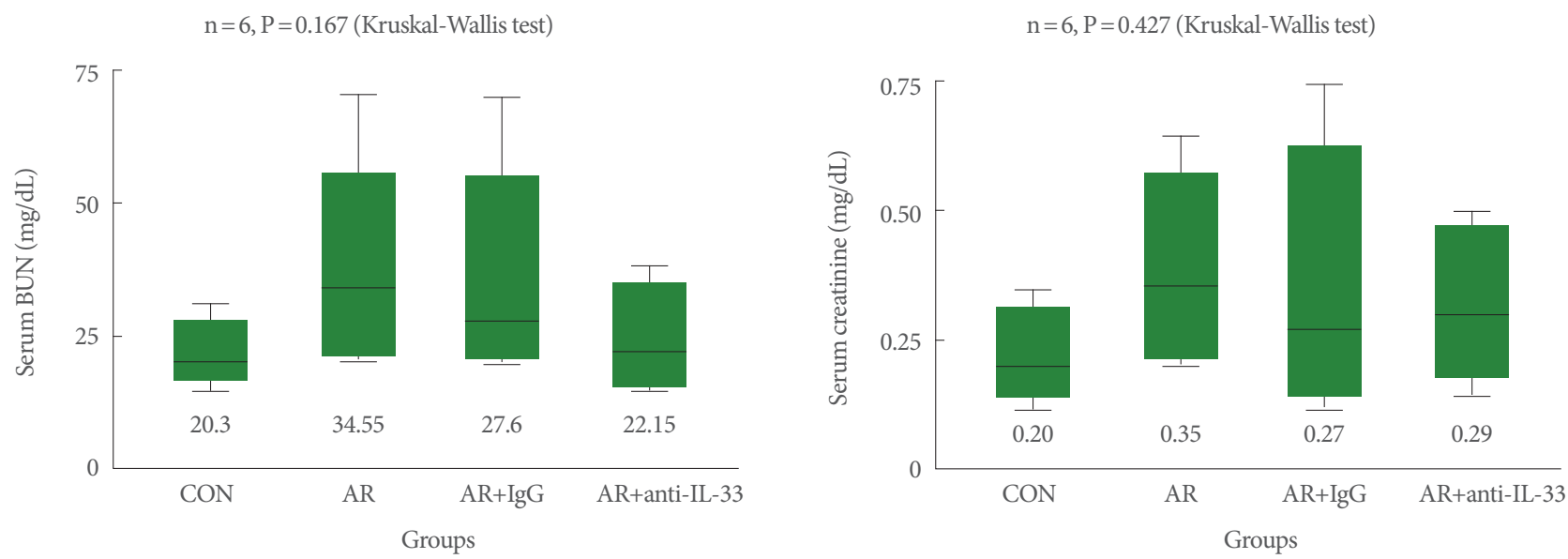

Fig. 1. Serum blood urea nitrogen (BUN) and creatinine levels. After inducing allergic rhinitis with ovalbumin (OVA), groups B (allergic group), $\mathrm{C}$ (null treatment group), and D (anti-IL-33 group) showed no significant increase in serum BUN and creatinine levels vs. group A (control group). CON, control; AR, allergic rhinitis; IL, interleukin. Kruskal-Wallis and Mann-Whitney U-test.

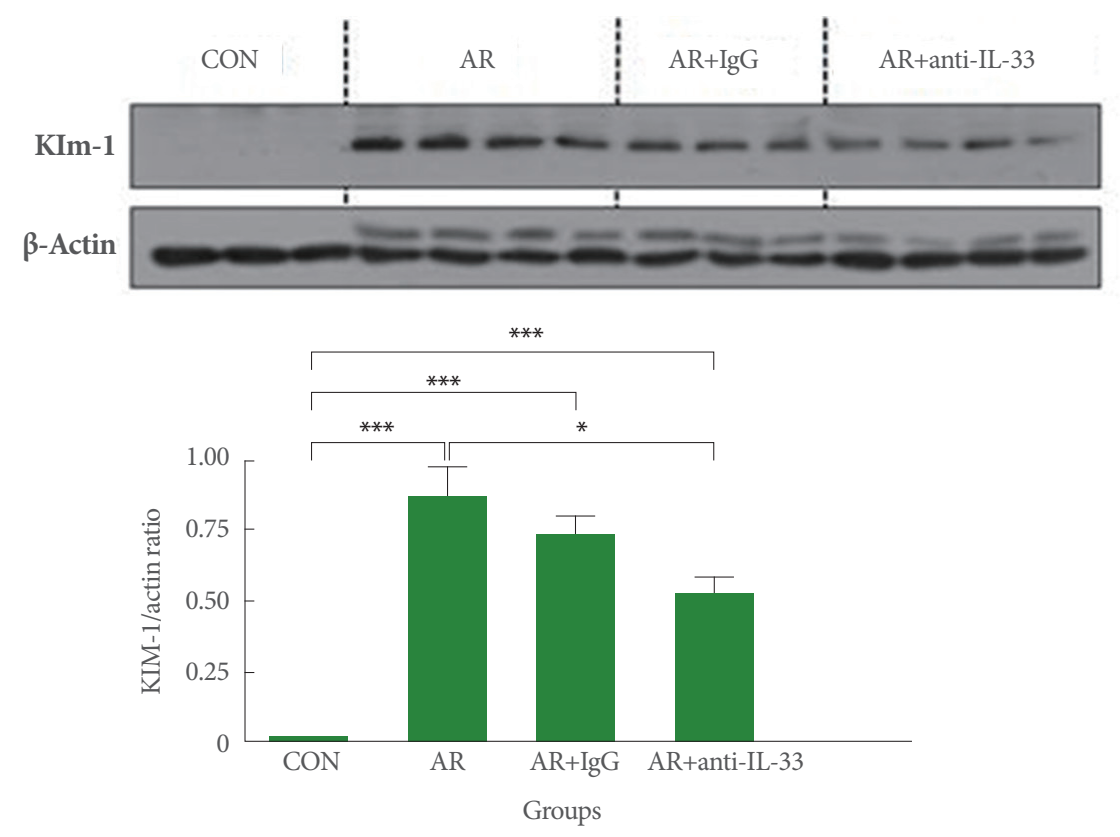

Fig. 2. Expression of kidney injury molecule-1 (KIM-1) protein in renal parenchyma. After ovalbumin challenge, mice in groups B (allergic group) and C (null treatment group) showed significant upregulation of KIM-1 protein expression. However, group D (antiIL-33 group) had significant lower KIM-1 protein levels than groups B and C. CON, control; AR, allergic rhinitis; IL, interleukin. Kruskal-Wallis and Mann-Whitney U-test, ${ }^{*} \mathrm{P}<0.05$. ${ }^{* * *} \mathrm{P}<0.001$. 
After treatment with anti-IL-33, mice in group D also showed no significant change in serum BUN and creatinine levels $(\mathrm{P}>0.05)$.

\section{Expression of KIM-1 Protein in Renal Tissue}

After the induction of allergic rhinitis with OVA, mice in group

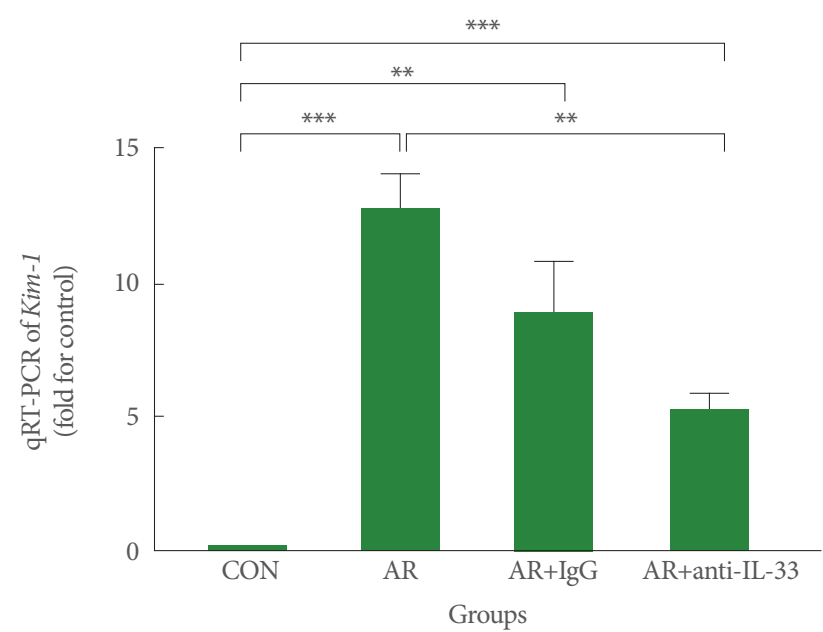

Fig. 3. Gene expression of Kim-1 mRNA in renal parenchyma. Mice in groups B (allergic group) and C (null treatment group) expressed significantly increased Kim-1 mRNA levels in renal tissues than mice in group A (control group) $(\mathrm{P}<0.001)$. However, mice in group D (anti-IL-33 group) expressed significantly lower Kim-1 mRNA levels than those in groups B and C $(\mathrm{P}<0.01)$. CON, control; AR, allergic rhinitis; IL, interleukin. Kruskal-Wallis and Mann-Whitney U-test. ${ }^{* *} \mathrm{P}<0.01$. ${ }^{* * *} \mathrm{P}<0.001$.
B showed significant increases in KIM-1 protein levels in renal tissues versus group A $(\mathrm{P}<0.001)$, as shown in Fig. 2 . The null treatment group $\mathrm{C}$ showed no significant change in KIM-1 protein levels versus group B. After IL-33 treatment, mice in group $\mathrm{D}$ showed significantly lower KIM-1 levels than mice in group $\mathrm{B}(\mathrm{P}<0.05)$ (Fig. 2).

\section{Expression of Kim-1 mRNA in Renal Tissue}

The Kim-1 expression levels in renal tissues in the 4 groups are shown in Fig. 3. Kim-1 expression levels were significantly higher in group $\mathrm{B}$ than group $\mathrm{A}(\mathrm{P}<0.001)$. There was no significant difference in Kim-1 expression levels between groups B and C. However, the Kim-1 expression levels in group D were significantly lower than group $\mathrm{B}(\mathrm{P}<0.01)$.

\section{Protein Expressions of COX-2 and iNOS in Renal Tissue}

Groups B and C expressed COX-2 protein in renal tissues at significantly higher levels than group $\mathrm{A}$, and group $\mathrm{D}$ expressed COX-2 protein at significantly lower levels compared to groups $\mathrm{B}$ and $\mathrm{C}(\mathrm{P}<0.05)$ (Fig. 4). No significant intergroup difference was observed for iNOS expression, although levels tended to be lower in group D (Fig. 4).

\section{Changes in the Levels of Proteins Involved in Renal Hemodynamics}

Group B expressed significantly lesser ${ }^{1177 \mathrm{Ser}} \mathrm{p}$-eNOS (expression and activity of e-NOS) and ${ }^{172 \mathrm{Thr}} \mathrm{p}$-AMPK (upstream kinase of

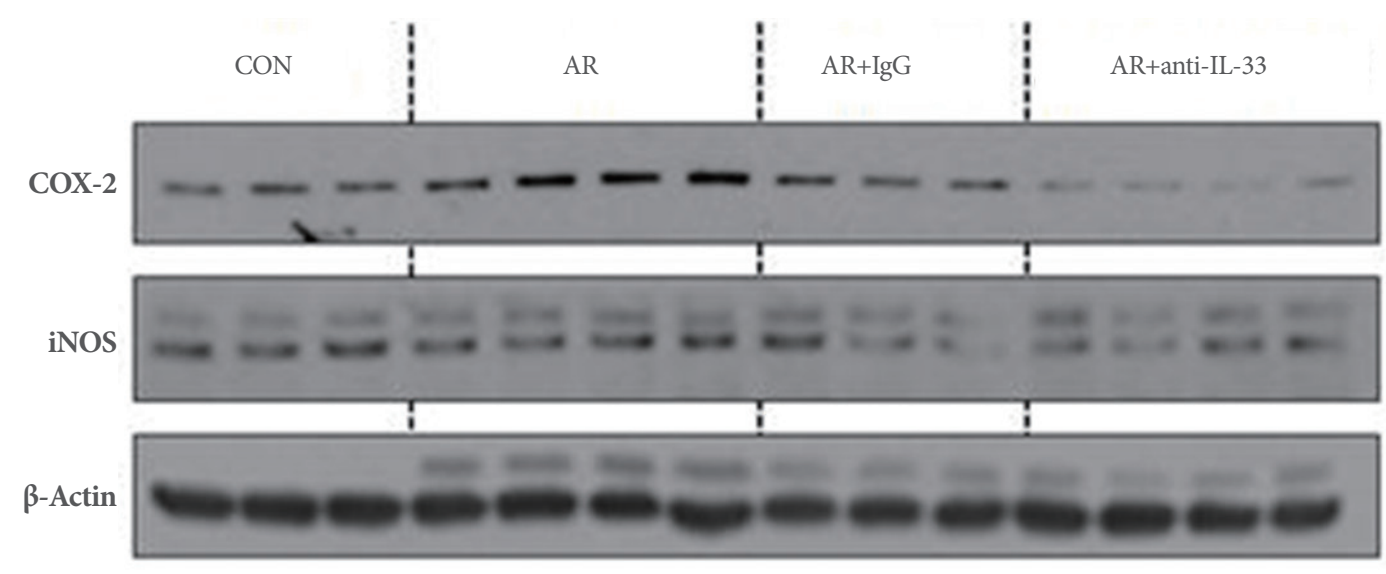

Fig. 4. Protein expressions of cyclooxygenase-2 (COX-2) and inducible nitric oxide synthase (iNOS) in renal parenchyma. Mice in groups B (allergic group) and C (null treatment group) expressed significantly higher COX-2 levels in renal tissues than mice in group A (control group), but mice in group D (anti-IL-33 group) expressed significantly lower COX-2 levels than mice in groups B and C $(\mathrm{P}<0.05)$. Group iNOS protein levels showed no significant difference, although levels tended to be lower in group D (P $>0.05)$. Kruskal-Wallis and Mann-Whitney U-test. CON, control; AR, allergic rhinitis; IL, interleukin. 


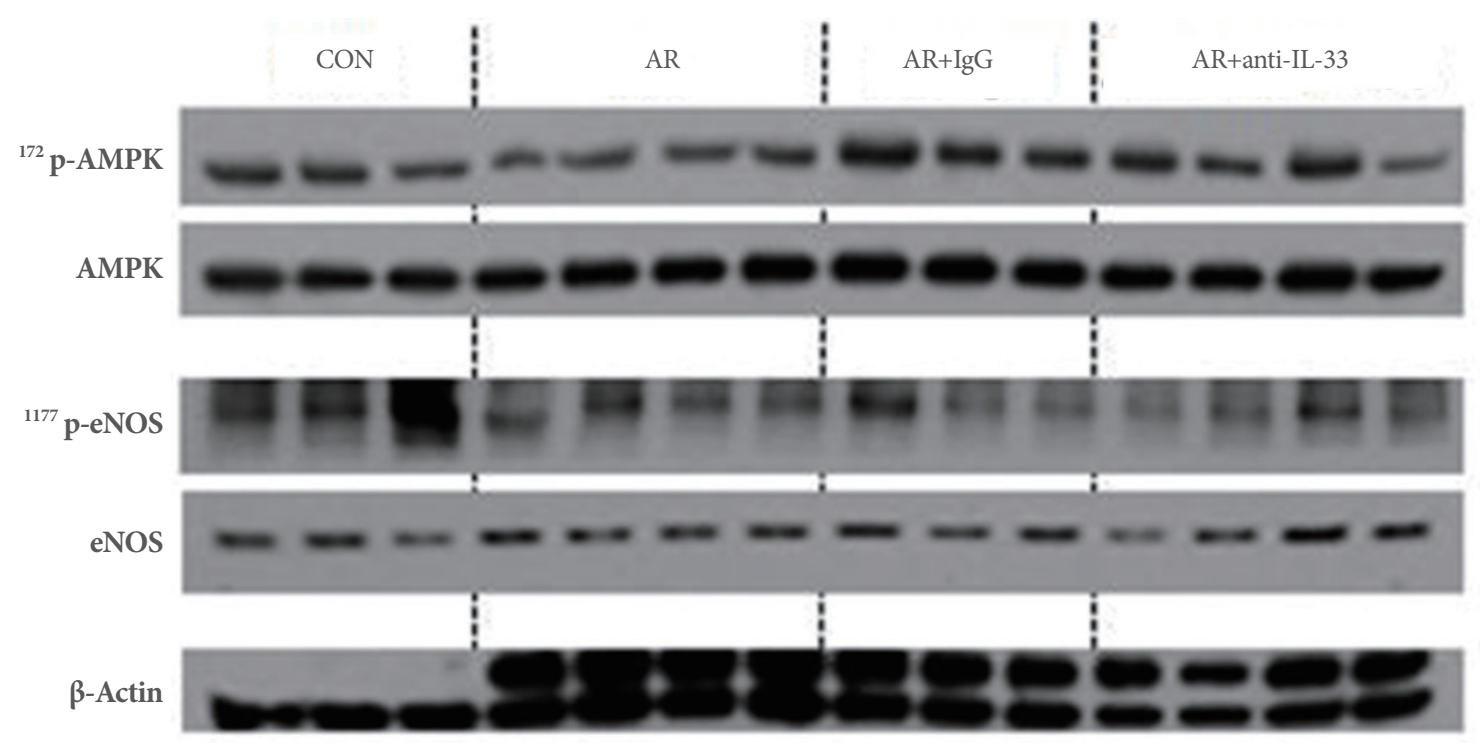

Fig. 5. Changes in the expressions of ${ }^{1177 \mathrm{Ser}} \mathrm{p}-\mathrm{eNOS}$ and ${ }^{172 \mathrm{Thr}}$ p-AMPK in renal parenchyma. Group D (anti-IL-33 group) showed modest recovery of ${ }^{1177 \mathrm{Ser}} \mathrm{p}$-eNOS and ${ }^{172 \mathrm{Thr}}$ - -AMPK expression as compared with groups B (allergic group) and C (null treatment group). Kruskal-Wallis and Mann-Whitney U-test. CON, control; AR, allergic rhinitis; IL, interleukin; p-eNOS, phosphorylated endothelial nitric oxide synthase; p-AMPK, phosphorylated AMP kinase.

eNOS) than group A. Group D showed modest recovery of ${ }^{1177 \mathrm{Ser}}$ p-eNOS and ${ }^{172 \mathrm{Thr}}$ p-AMPK expression (Fig. 5).

\section{DISCUSSION}

IL-33 is a type of 'alarmin', and is released in its intact, active form from injured epithelial or endothelial cells. Thus, IL-33 could be involved in inflammatory response in any organ with an epithelial or endothelial lining. Reports indicate that IL-33 could also be involved in the pathophysiology of AKI. Akcay et al. [7] reported that IL-33 was significantly increased in mice with cisplatin-induced AKI, and suggested that soluble ST2 (sST2, a decoy receptor of IL-33) has a protective effect, as demonstrated by reduced numbers of $\mathrm{CD} 4^{+} \mathrm{T}$ lymphocytes, tubular necrosis, and apoptosis. Bao et al. [6] found that sST2 was significantly increased in the serum of patients with chronic kidney disorders, and that its concentration was significantly correlated with disease severity. Furthermore, the prevalence of acute or chronic renal diseases has been reported to be significantly greater in individuals with allergic diseases [19]. However, the effect of anti-IL-33 on renal injury has not been analyzed in detail. To the best of our knowledge, this is the first study to evaluate the protective effect of anti-IL-33 in a murine model of AKI.

Han et al. [11] had earlier reported that Kim-1 could be a useful marker for renal proximal tubular injury in patients with acute renal tubular injury. We designed this study to extend this clinical efficacy of Kim-1 to an 'experimentally induced' murine model of AKI as well. In the present study, the mice showed no significant changes in serum BUN and creatinine levels after OVA challenge. Nevertheless, KIM-1 protein expression was significantly increased by OVA challenge. After AKI induction, systemic release of KIM-1 protein by tubular epithelial cells has been reported to increase significantly [20,21], which suggested that Kim-1 might be a clinically useful biomarker for the diagnosis and evaluation of AKI [20-22]. In this study, significant increases in Kim-1 levels in renal parenchyma further support its potential use as a sensitive biomarker of early stage AKI.

Mice in group D (the anti-IL-33 group) expressed significantly lesser Kim-1 than mice in groups B and C. IL-33 is released from injured epithelial cells in its active form, and binds to ST2 receptor on nearby epithelial cells to increase pro-inflammatory cytokine production, and thus, exacerbate AKI $[11,17]$. On the other hand, anti-IL-33 to IL-33 binding could competitively inhibit ST2 receptor binding of IL-33, reduce renal injury, reduce Kim-1 levels.

COX-2 expression was significantly higher in groups B and $\mathrm{C}$ and lower in group $\mathrm{D}$ as compared to group $\mathrm{A}$, which concurs with our previous findings [23]. COX-2 inhibition has an antiallergic effect via the downregulation of prostaglandin D2 
[24], and thus, the antiallergic effect of anti-IL-33 might also be related to COX-2 inhibition. On the other hand, iNOS protein levels were not significantly different between the four groups, although it tended to be lower in group D. In our previous study on mice with allergic asthma, iNOS protein expression was significantly higher in mice with allergic asthma and this increase was effectively suppressed by treating lung tissues with anti-IL-33 [25]. However, the role of iNOS and nitric oxide in the glomerulus have been extensively debated. Some researchers suggest that nitric oxide and reactive nitrogen species are associated with apoptotic and necrotic death in mesangial cells $[26,27]$. However, others argue that peroxynitrite and nitrosative stress had only minimal toxic effect on mesangial cells. Instead, iNOS inhibition caused fibronectin deposition, proteinuria, and hypercellularity $[28,29]$. We believe iNOS plays a pivotal role in allergic inflammation of lung, but its role in AKI is limited.

AMPK can sense and regulate cellular energy homeostasis as well as regulates neuronal survival [30]. However, no study has specifically addressed the role of AMPK in allergic inflammation. According to Hwang et al. [31], AMPK-knockout mice exhibited increased the high-affinity receptor for IgE (FceRI) -mediated mast cell activation and anaphylaxis. When metformin (an AMPK activator) was given to obese mice with allergic rhinitis for the treatment of insulin resistance, the mice showed significantly less eosinophilic infiltration and fewer inflammatory cells in bronchoalveolar lavage fluid [32]. On the other hand, in a mouse model of OVA-induced asthma, transgenic mice overexpressing eNOS showed significantly lower interferon- $\gamma$, IL-5 and IL-10 titers, fewer eosinophils and lymphocytes in bronchoalveolar lavage fluid, and less hyperresponsiveness to methacholine than wild type mice [33]. eNOS-overexpressing transgenic mice also showed less eosinophilic accumulation and lower responsiveness to acetylcholine challenge and eotaxin [34]. However, in the present study, eNOS expression did not change significantly after treatment with anti-IL-33. Therefore, it is possible that the protective effect of anti-IL-33 against AKI is independent of AMPK and eNOS.

One limitation to the present study is that histopathological analysis of renal parenchyma was not conducted. Although it is likely that histological changes were minimal, this aspect should be confirmed by further studies. Binding of IL-33 to ST2 increases production of proinflammatory cytokines. On the other hand, reduced expression of COX-2 due to anti-IL-33 treatment could downregulate prostaglandin D2. Evaluation of ST2 expression and D2 levels could yield meaningful data. Also, measurement of serum IL-33 and correlating its levels with Kim-1 and COX-2 expression levels in renal parenchyma, would further validate our conclusions. Furthermore, immunohistochemical staining for Kim-1 in renal parenchyma can provide useful information. Beta 2-microglobulin is known to have higher sensitivity to and specificity for AKI, and its evaluation would contribute important information in follow-up studies. Therefore, we intend to conduct studies with a larger sample size of mice to address these aspects and improve our understanding of the effect of anti-IL-33 on renal injury.

In conclusion, Kim-1 could be a useful marker for detecting early-stage renal injury in mouse models of OVA-induced AKI. Furthermore, our findings indicate that anti-IL-33 administration has a beneficial effect on mouse models of OVA-induced AKI.

\section{REFERENCES}

1. Baekkevold ES, Roussigné M, Yamanaka T, Johansen FE, Jahnsen FL, Amalric F, et al. Molecular characterization of NF-HEV, a nuclear factor preferentially expressed in human high endothelial venules. Am J Pathol 2003;163:69-79.

2. Kurowska-Stolarska M, Hueber A, Stolarski B, McInnes IB. Interleukin-33: a novel mediator with a role in distinct disease pathologies. J Intern Med 2011;269:29-35.

3. Smith DE. IL-33: a tissue derived cytokine pathway involved in allergic inflammation and asthma. Clin Exp Allergy 2010;40:200-8.

4. Lüthi AU, Cullen SP, McNeela EA, Duriez PJ, Afonina IS, Sheridan C, et al. Suppression of interleukin-33 bioactivity through proteolysis by apoptotic caspases. Immunity 2009;31:84-98.

5. Tago K, Noda T, Hayakawa M, Iwahana H, Yanagisawa K, Yashiro T, et al. Tissue distribution and subcellular localization of a variant form of the human ST2 gene product, ST2V. Biochem Biophys Res Commun 2001;285:1377-83.

6. Bao YS, Na SP, Zhang P, Jia XB, Liu RC, Yu CY, et al. Characterization of interleukin-33 and soluble ST2 in serum and their association with disease severity in patients with chronic kidney disease. J Clin Immunol 2012;32:587-94.

7. Akcay A, Nguyen Q, He Z, Turkmen K, Won Lee D, Hernando AA, et al. IL-33 exacerbates acute kidney injury. J Am Soc Nephrol 2011;22:2057-67.

8. Yu TM, Palanisamy K, Sun KT, Day YJ, Shu KH, Wang IK, et al. RANTES mediates kidney ischemia reperfusion injury through a possible role of HIF-1 $a$ and LncRNA PRINS. Sci Rep 2016;6: 
18424.

9. Jang TY, Kim YH. Interleukin-33 and mast cells bridge innate and adaptive immunity: from the allergologist's perspective. Int Neurourol J 2015;19:142-50.

10. Hoffmann D, Adler M, Vaidya VS, Rached E, Mulrane L, Gallagher WM, et al. Performance of novel kidney biomarkers in preclinical toxicity studies. Toxicol Sci 2010;116:8-22.

11. Han WK, Bailly V, Abichandani R, Thadhani R, Bonventre JV. Kidney injury molecule-1 (KIM-1): a novel biomarker for human renal proximal tubule injury. Kidney Int 2002;62:237-44.

12. Breyer MD, Harris RC. Cyclooxygenase 2 and the kidney. Curr Opin Nephrol Hypertens 2001;10:89-98.

13. Funk CD. Prostaglandins and leukotrienes: advances in eicosanoid biology. Science 2001;294:1871-5.

14. Nørregaard R, Madsen K, Hansen PB, Bie P, Thavalingam S, Frøkiær J, et al. COX-2 disruption leads to increased central vasopressin stores and impaired urine concentrating ability in mice. Am J Physiol Renal Physiol 2011;301:F1303-13.

15. Wei L, Chen W, Zou Y, Huang H, Pan B, Jin S, et al. AMP-activated protein kinase regulates autophagic protection against cisplatin-induced tissue injury in the kidney. Genet Mol Res 2015;14:12006-15.

16. Kim YH, Yang TY, Park CS, Ahn SH, Son BK, Kim JH, et al. AntiIL-33 antibody has a therapeutic effect in a murine model of allergic rhinitis. Allergy 2012;67:183-90.

17. Saito H, Matsumoto K, Denburg AE, Crawford L, Ellis R, Inman $\mathrm{MD}$, et al. Pathogenesis of murine experimental allergic rhinitis: a study of local and systemic consequences of IL-5 deficiency. J Immunol 2002;168:3017-23.

18. Kim YH, Park CS, Lim DH, Ahn SH, Son BK, Kim JH, et al. Beneficial effect of anti-interleukin-33 on the murine model of allergic inflammation of the lower airway. J Asthma 2012;49:738-43.

19. Filiopoulos V, Vlassopoulos D. Inflammatory syndrome in chronic kidney disease: pathogenesis and influence on outcomes. Inflamm Allergy Drug Targets 2009;8:369-82.

20. Charlton JR, Portilla D, Okusa MD. A basic science view of acute kidney injury biomarkers. Nephrol Dial Transplant 2014;29:130111.

21. Amin RP, Vickers AE, Sistare F, Thompson KL, Roman RJ, Lawton $\mathrm{M}$, et al. Identification of putative gene based markers of renal toxicity. Environ Health Perspect 2004;112:465-79.

22. Huang Y, Don-Wauchope AC. The clinical utility of kidney injury molecule 1 in the prediction, diagnosis and prognosis of acute kidney injury: a systematic review. Inflamm Allergy Drug Targets 2011;10:260-71.

23. Jang TY, Park CS, Kim KS, Heo MJ, Kim YH. Benzaldehyde sup- presses murine allergic asthma and rhinitis. Int Immunopharmacol 2014;22:444-50.

24. Li X, Lu Y, Jin Y, Son JK, Lee SH, Chang HW. Curcumin inhibits the activation of immunoglobulin e-mediated mast cells and passive systemic anaphylaxis in mice by reducing serum eicosanoid and histamine levels. Biomol Ther (Seoul) 2014;22:27-34.

25. Park CS, Jang TY, Heo MJ, Jung AY, Kim YH. Antiallergic effects of anti-interleukin-33 are associated with suppression of immunoglobulin light chain and inducible nitric oxide synthase. Am J Rhinol Allergy 2016;30:17-22.

26. Hwang I, Lee J, Huh JY, Park J, Lee HB, Ho YS, et al. Catalase deficiency accelerates diabetic renal injury through peroxisomal dysfunction. Diabetes 2012;61:728-38.

27. Hruby Z, Beck KF. Cytotoxic effect of autocrine and macrophagederived nitric oxide on cultured rat mesangial cells. Clin Exp Immunol 1997;107:76-82.

28. Satriano J, Lortie MJ, Ishizuka S, Valdivielso JM, Friedman B, Munger KA. Inhibition of inducible nitric oxide synthase alters Thy-1 glomeruonephritis in rats. Nephron Physiol 2006;102:p1726.

29. Westenfeld R, Gawlik A, de Heer E, Kitahara M, Abou-Rebyeh F, Floege J, et al. Selective inhibition of inducible nitric oxide synthase enhances intraglomerular coagulation in chronic anti-Thy 1 nephritis. Kidney Int 2002;61:834-8.

30. Kim HS, Moon S, Paik JH, Shin DW, Kim LS, Park CS, et al. Activation of the 5'-AMP-activated protein kinase in the cerebral cortex of young senescence-accelerated P8 mice and association with GSK3 3 - and PP2A-dependent inhibition of $\mathrm{p}-\mathrm{tau}_{396}$ expression. J Alzheimers Dis 2015;46:249-59.

31. Hwang SL, Lu Y, Li X, Kim YD, Cho YS, Jahng Y, et al. ERK1/2 antagonize AMPK-dependent regulation of FceRI-mediated mast cell activation and anaphylaxis. J Allergy Clin Immunol 2014;134:71421.e7.

32. Calixto MC, Lintomen L, Andre DM, Leiria LO, Ferreira D, LellisSantos C, et al. Metformin attenuates the exacerbation of the allergic eosinophilic inflammation in high fat-diet-induced obesity in mice. PLoS One 2013;8:e76786.

33. Ten Broeke R, De Crom R, Van Haperen R, Verweij V, LeusinkMuis T, Van Ark I, et al. Overexpression of endothelial nitric oxide synthase suppresses features of allergic asthma in mice. Respir Res 2006;7:58.

34. Kobayashi K, Nishimura Y, Yamashita T, Nishiuma T, Satouchi M, Yokoyama M. The effect of overexpression of endothelial nitric oxide synthase on eosinophilic lung inflammation in a murine model. Int Immunopharmacol 2006;6:1040-52. 